\title{
$\begin{array}{ll}\text { Research Square } & \begin{array}{l}\text { Preprints are preliminary reports that have not undergone peer review. } \\ \text { They should not be considered conclusive, used to inform clinical practice, }\end{array} \\ \text { or referenced by the media as validated information }\end{array}$
}

\section{Oxytocin levels in individuals with schizophrenia are high in cerebrospinal fluid but low in serum: A systematic review and meta-analysis.}

Yazmin Hernández-Díaz

UJAT: Universidad Juarez Autonoma de Tabasco

Thelma Beatriz González-Castro

UJAT: Universidad Juarez Autonoma de Tabasco

Carlos Tovilla-Zarate ( $\nabla$ alfonso_tovillaz@yahoo.com.mx )

Universidad Juarez Autonoma de Tabasco Division Academia de Ciencias de la Salud https://orcid.org/0000-0001-

8170-8171

María Lilia López-Narváez

UJAT: Universidad Juarez Autonoma de Tabasco

Alma Delia Genis-Mendoza

INMEGEN: Instituto Nacional de Medicina Genomica

Rosa Giannina Castillo-Avila

UJAT: Universidad Juarez Autonoma de Tabasco

Miguel Ángel Ramos-Méndez

UJAT: Universidad Juarez Autonoma de Tabasco

Isela Esther Juárez-Rojop

UJAT: Universidad Juarez Autonoma de Tabasco

\section{Research Article}

Keywords: oxytocin, schizophrenia, serum, cerebrospinal fluid

Posted Date: March 30th, 2021

DOI: https://doi.org/10.21203/rs.3.rs-260914/v1

License: (c) This work is licensed under a Creative Commons Attribution 4.0 International License. Read Full License 


\section{Abstract}

Schizophrenia is a mental and disabling disease. Levels of oxytocin have been proposed as a biomarker of schizophrenia; however, the observed levels of oxytocin in individuals with schizophrenia have been inconsistent across studies. We performed a meta-analysis to evaluate oxytocin levels in plasma, serum and cerebrospinal fluid to see if there are statistically different concentrations between individuals with schizophrenia and the comparison group.

The meta-analysis followed the Preferred Reporting Items for Systematic Reviews and Meta-Analyses (PRISMA) statement to guarantee a high quality and reproducibility.

Following the inclusion and exclusion criteria, 14 studies were included in the meta-analysis. The quality of the study was evaluated by the Newcastle-Ottawa Scale (NOS). A random-effects model was performed using the Comprehensive Metaanalysis software with the standardized mean difference (SMD) and 95\% confidence intervals (Cls).Serum oxytocin levels in individuals with schizophrenia were significantly lower than that in comparison group $(\mathrm{SMD}=-1.74,95 \% \mathrm{Cl}=-3.22$ to - 0.26, $p=0.02$ ) but cerebrospinal fluid oxytocin levels in individuals with schizophrenia were significantly higher than those in the comparison group $(\mathrm{SMD}=0.55,95 \% \mathrm{Cl}=0.05$ to $1.04, \mathrm{p}=0.03)$.

Our results suggest that oxytocin levels in cerebrospinal fluid are increased in individuals with schizophrenia but decreased in serum. Therefore, the oxytocin system dysregulation may play a role in the pathophysiology of schizophrenia and it should be measured in more populations for a possible implementation as a biomarker of schizophrenia.

\section{Introduction}

There are numerous environmental, biological and genetic factors that interact and contribute to the vulnerability or resilience to develop schizophrenia (SCZ). Schizophrenia is a devastating mental illness; it is highly heritable, chronic, severe and disabling neurodevelopmental brain disease. Schizophrenia is characterized by positive, negative and cognitive symptoms. Positive symptoms consist of psychotic symptoms such as hallucinations, delusions that are often paranoid, as well as disorganized speech and behavior. Negative symptoms include flattened affect, poverty of speech, loss of a sense of pleasure and loss of interests and drive; while cognitive symptoms comprise deficits in attention, working memory, and in executive functions (Owen et al., 2016; Perkovic et al., 2017).

Onset symptoms of schizophrenia typically occur in early adult life and occur earlier in men than in women (Nadeem et al., 2004; Schultz et al., 2007). The etiology of SCZ is multifactorial and reflects an interaction between genetic and environmental contributors. Some risk factors include family history, social isolation, urbanicity, pregnancy and birth complications, acute life events, developmental difficulties, central nervous system infections in childhood and substance abuse (Stilo and Murray, 2019; Wahlberg et al., 2004).

Nowadays, biomarkers and indicators of schizophrenia diagnosis or the severity of the disease are highly necessary. Biomarkers that can be easily available are body fluids that could help in the (1) diagnostic, (2) prognostic, or (3) prediction of individual response to a particular therapy (theranostics) (Weickert et al., 2013). Many biomarkers have been proposed in schizophrenia (Liu et al., 2021), including oxytocin.

Oxytocin (Oxt) is a neuropeptide synthesized primarily in neurons of the hypothalamic supraoptic and paraventricular nuclei. The Oxt system is involved in the neuromodulation of social behaviors, affiliative behaviors and aggression. Altered levels of Oxt have been reported in individuals with SCZ; therefore, the Oxt system could be linked to the pathophysiology of schizophrenia (Aydın et al., 2019; Goldman et al., 2008; Rubin et al., 2010). 
Up to today, the mechanism concerning the effect of oxytocin as a risk factor for developing SCZ is unknown. However, many association studies have shown that individuals with schizophrenia have decreased levels of Oxt. Therefore, the aim of this systematic review and meta-analysis of case-control studies was to evaluate the effect Oxt levels on individuals with schizophrenia and to explore differences in Oxt levels between individuals with SCZ and healthy subjects. Additionally, we examined effects of potential confounding factors that may have an impact on these relationships.

\section{Materials And Methods \\ Data sources and search strategy}

The electronic databases PubMed, Scopus and EBSCO were searched for articles that included one or more keywords: "oxytocin" OR "oxytocin level” OR "plasma oxytocin" OR "serum oxytocin" OR “CSF oxytocin" AND "schizophrenia" OR "schizophrenia spectrum disorders". The reference lists of the retrieved articles were then reviewed to identify additional studies. The protocol for this systematic review and meta-analysis was registered in PROSPERO (CRD42020221590) and can be accessed on: (https://www.crd.york.ac.uk/PROSPERO/display_record.php?RecordID=221590).

The meta-analysis was conducted following the Preferred Reporting Items for Systematic Reviews and Meta-analyses (PRISMA) guidelines.

We restricted the search to studies in humans published in English.

\section{Study selection}

In this systematic review we included studies that evaluated oxytocin concentrations in individuals with schizophrenia; these studies had to fulfill the following criteria: (1) studied individuals diagnosed with schizophrenia spectrum disorders;

(2) the study design had to be a case-control study that reported values in mean and standard deviation of oxytocin levels or had enough data to calculate these values; (3) compared the levels of oxytocin between two groups of individuals, those with SCZ and a healthy control group, and (4) publications in peer-reviewed journals.

The following type of studies were excluded: (1) reviews, case reports, case-only studies, animal studies, and simple commentaries; (2) overlapping publications and (3) publications lacking measures of Oxt levels.

The selection process was independently completed by our research team and any discrepancy or disagreement was resolved by discussion until consensus was reached among the reviewers.

\section{Data extraction and quality assessment}

Two authors (YHD and TBGC) extracted data using a structured form not blinded to study results, author names or institutions. This form included study data and participants description. The methodological quality of included studies was evaluated using the Newcastle-Ottawa scale (NOS) by two investigators (YHD and TBGC). Disagreements were resolved by a third reviewer (CATZ). The quality scale consists of three parts: selection, comparability and exposure assessment. High-quality response earns a point, totaling up to nine points (the comparability question earns up to two points). The total is calculated by adding the points of all categories. In our meta-analysis, we considered 6 points or higher as a good-quality study.

\section{Statistical analysis}

The Comprehensive Meta-analysis version 2 (Biostat, Englewood, NJ, USA) software was used to deal with quantitative data. Standardized mean differences (SMD) were calculated and represented the differences in the mean oxytocin levels between individuals with SCZ and healthy controls; with 95\% confidence intervals (Cl) and were illustrated by forest plots. 
Heterogeneity was evaluated by Q-test and $\mathrm{I}^{2}$-test. Generally, if $\mathrm{p}<0.05$ (Q-test) or $\mathrm{I}^{2}$-test $>50 \%$, when heterogeneity was thought to exist, the random-effect models was used. Heterogeneity is the systematic difference between the results of the studies that cannot be attributed simply to chance. We analyzed subgroups of studies to examine the source of potential heterogeneity based on the region, analytical methods and gender.

Potential publication bias was explored by using funnel plot and Egger line regression test (Egger's test). Sensitivity analyses were conducted to evaluate the stability of pooled results. All tests were two-sided and a p value of $<0.05$ was considered statistically significant.

\section{Results}

\section{Systematic review}

The PRISMA flow diagram of the study selection used in this meta-analysis is shown in Figure 1. A total of 309 articles associated with the searched keywords were first identified. Of these articles, 145 were excluded based on the titles and key words; the full texts of 164 studies were obtained and 147 more papers were eliminated. Eventually, 17 studies were enrolled in this systematic review (Aydın et al., 2019; Beckmann et al., 1985; Glovinsky et al., 1994; Goldman et al., 2008; Guzel et al., 2018; Jobst et al., 2014; Kéri et al., 2009; Liu et al., 2019; Rubin et al., 2014; Rubin et al., 2013; Rubin et al., 2010; Rubin et al., 2018; Sasayama et al., 2012; Speck et al., 2019; Strauss et al., 2019; Strauss et al., 2015; Walss-Bass et al., 2013).

The characteristics of the seventeen selected studies are presented in Table 1. All the studies were published between 1985 and 2019. Eight studies were conducted in the United States, three in Germany, two in Turkey, one in Japan, one in Hungary, one in Portugal and one in China.

The sample sizes ranged from 15 to 60 in individuals with schizophrenia and from 7 to 66 in controls. Enzyme-linked immunosorbent assay (ELISA) and radioimmunoassay (RIA) methods were implemented for the detection of Oxt levels. We identified three different biomaterials used for Oxt assays: plasma, serum and cerebro-spinal fluid (CSF). Therefore, three meta-analysis were carried out, additionally, subgroup analyses were performed for each one of them based on data availability.

Finally, the study-specific quality is summarized in Figure 2. All studies were awarded $\geq 7$ points and were defined as good-quality studies.

Meta-analysis of plasma oxytocin levels in SCZ

First, the analysis included 214 individuals with schizophrenia and 136 individuals in the comparison group. In this analysis six studies were included (Aydın et al., 2019; Goldman et al., 2008; Speck et al., 2019; Strauss et al., 2019; Strauss et al., 2015; Walss-Bass et al., 2013). Table 1. The meta-analysis suggested no statistical differences between plasma oxytocin levels between individuals with schizophrenia and the comparison group (SMD=-0.27, 95\% $\mathrm{Cl}:-1.10$ to 0.55 $\mathrm{Pg} / \mathrm{mL}, \mathrm{p}=0.51, \mathrm{I}^{2}=71, \mathrm{p}(\mathrm{Q})<0.01$. (Table 2).

Meta-analysis of serum oxytocin levels in SCZ

Second, we evaluated oxytocin levels in serum and found that these values were lower in cases than in the control group. This meta-analysis included five studies 209 individuals with schizophrenia and 221 individuals in the comparison group (Guzel et al., 2018; Liu et al., 2019; Rubin et al., 2013; Rubin et al., 2010; Rubin et al., 2018). Table 1. The meta-analysis showed that serum oxytocin levels in SCZ individuals were significantly lower than in the comparison group (SMD = $1.74,95 \% \mathrm{Cl}=-3.22$ to $\left.-0.26 \mathrm{Pg} / \mathrm{mL}, \mathrm{p}=0.02, \mathrm{I}^{2}=77 \mathrm{p}(\mathrm{Q})<0.01\right)$. Table 2. Figure 3 . 
The results of the subgroup analysis are shown in Table 2. The method of evaluation (ELISA) showed a significant association of decreased oxytocin levels in individuals with schizophrenia. Other subgroups did not show statistical differences. Table 2.

\section{Meta-analysis of CSF oxytocin levels in SCZ}

Finally, a third meta-analysis was conducted using three studies (Beckmann et al., 1985; Glovinsky et al., 1994; Sasayama et al., 2012) comprising 95 individuals with schizophrenia and 52 individuals in the comparison group (Table 1). The results of the meta-analysis indicated that cerebro-spinal fluid oxytocin levels in individuals with schizophrenia were significantly higher than in individuals of the comparison group $\left(S M D=0.55,95 \% \mathrm{Cl}=0.05\right.$ to $1.04, p=0.03, I^{2}=50 \%$, $\mathrm{p}(\mathrm{Q})=0.03)$.

Meta-regression analyses

The following covariates were considered for meta-regression: mean age and gender. The results showed that mean age contributed to effect in the meta-analysis (Plasma, slope $=-4.38,95 \% \mathrm{Cl}=-6.24 ;-2.53, \mathrm{P}=0.001$ and Serum, slope = $-1.98,95 \% \mathrm{Cl}=-3.11 ;-0.84, \mathrm{P}=0.006)$. The meta-regression model also showed significant results in the analysis by gender (Plasma, slope $=-1.77,95 \% \mathrm{Cl}=-2.45 ;-1.10, \mathrm{P}=0.001$ and Serum, slope $=6.90,95 \% \mathrm{Cl}=5.20 ; 8.61, \mathrm{P}=0.001$ ).

\section{Sensitivity analysis and publication bias}

The sensitivity analysis indicated that the exclusion of none of the primary studies influenced the pooled estimates. For publication bias, the funnel plot was symmetric (Figure 4). Moreover, Egger's tests did not reveal significant evidence of publication bias among the included studies (Table 2).

\section{Discussion}

A biomarker refers to a molecular change in body tissues and fluids that can be used as a clinical indicator of a disease; in this case, the biomarker will allow better diagnostic procedures and therapeutic strategies in individuals with schizophrenia (Perkovic et al., 2017; Vargas, 2014). The use of biomarkers that can be measured or determined from easily available body fluids such as serum or cerebrospinal fluid is highly recommended. As oxytocin acts centrally within the brain to control behavior, it has been suggested as biomarker of mental disorders. Oxytocin is a highly conserved neuropeptide produced in the hypothalamus, it has modulatory effects on a variety of social and non-social behaviors such as affiliation, stress, memory and learning (Churchland and Winkielman, 2012; Jones et al., 2017).

In the meta-analysis, we included fourteen studies that comprised 518 cases and 409 controls. Interestingly, we found that Oxt levels were lower in serum samples of individuals with SCZ but higher in CSF samples of individuals with SCZ.

A possible explanation for the increased Oxt levels in patients with schizophrenia could be that the release of Oxt contributes to the modulation and maintenance of other hormones such as cortisol, which could increase the response to the stressful stimuli (Donadon et al., 2018; Liu et al., 2019). Then, stressful experiences might alter the functioning of the suprachiasmatic nucleus altering the release of endogenous Oxt (Donadon et al., 2018; Liu et al., 2019). On the other hand, it has been proposed that low levels of serum oxytocin in individuals with acute schizophrenia are associated with the functionality of the patient, the severity of the disease and with the severity of the positive symptoms (Guzel et al., 2018). This could explain the contrasting observations regarding oxytocin concentrations in the central system (high in schizophrenia) and in blood (low in schizophrenia); nevertheless, more studies are necessary in order to confirm and understand what causes those differences. As we observed in our meta-analysis, oxytocin concentrations in cerebrospinal fluid indicated that were significantly higher in individuals with schizophrenia than in controls. Beckmann et al. (Beckmann et al., 1985) reported increased concentrations of oxytocin in schizophrenic patients, and they were higher in 
those receiving neuroleptic treatment. In addition, oxytocin concentrations increased after three weeks of neuroleptic treatment. However, another study did not fully support these results (Sasayama et al., 2012); therefore, more data are required to fully explore this relationship.

In our meta-analysis we evaluated several confounding factors in order to identify those that could impact the relationship between Oxt levels and SCZ. For instance, different analytical methods to measure oxytocin concentrations were used among the studies. Subgroup analyses revealed that Oxt levels were significantly lower in patients with SCZ compared to controls when the concentrations were measured through ELISA; suggesting that ELISA assays may have been more sensitive in detecting Oxt levels. All in all, we need more studies to confirm the effect of Oxt levels on individuals with schizophrenia, using unit methods in order to improve the accuracy and reliability of the results.

Our study had some advantages. First, the sensitivity analyses indicated that the removal of individual studies did not alter the final results, which increased the robustness of our conclusions. Second, no significant publication bias was detected, suggesting that the results are also reliable. On the other hand, our meta-analysis also presents some limitations. Firstly, the number of studies included was small and stratified analyses might have lower power to identify potential confounding factors. Secondly, there was significant heterogeneity in this analysis, which may have affected the precision of the overall results. Thirdly, we observed opposing patterns of findings observed for serum vs. CSF. This is important, because according the source and origin of oxytocin, its mechanism can be different. Finally, the present metaanalysis focused only on studies published in English, the ones reported in other languages might have changed the present results.

\section{Conclusions}

In summary, the present meta-analysis found increased levels oxytocin in CSF but decreased levels of oxytocin in serum. These results suggests that the oxytocin system dysregulation may play a role in the pathophysiology of schizophrenia. Oxt could be an interesting candidate in the search for biomarkers that could improve diagnosis and evaluation of patients with schizophrenia. Nonetheless, more well-designed and large-scale studies are needed to continue investigating the mechanisms and mediating factors for these findings.

\section{Declarations}

\section{Compliance with Ethical Standards}

\section{Funding}

None

\section{Conflicts of interest}

All the authors declare no conflict of interest.

\section{Ethical approval}

This article does not contain any studies with human participants performed by any of the authors.

\section{Data availability}

Not aplicable

\section{Acknowledgements}


None

\section{Author contributions}

YHD, TBGC, CATZ and IEJR participated in planning the study, data analysis, and drafting the manuscript. RGCA and MARM assisted and helped in all analysis. MLLN and ADGM supervised the study, participated in data analysis, and drafted the manuscript.

\section{References}

Aydın, O., Balıkçı, K., Taş, C., Ünal-Aydın, P., Taneli, F., Esen-Danacı, A., 2019. Assessing the relationship between attachment, parental attitude and plasma oxytocin in schizophrenia patients and their unaffected siblings. Nord $\mathrm{J}$ Psychiatry 73, 51-57.

Beckmann, H., Lang, R.E., Gattaz, W.F., 1985. Vasopressin-oxytocin in cerebrospinal fluid of schizophrenic patients and normal controls. Psychoneuroendocrinology 10, 187-191.

Churchland, P.S., Winkielman, P., 2012. Modulating social behavior with oxytocin: how does it work? What does it mean? Horm Behav 61, 392-399.

Donadon, M.F., Martin-Santos, R., Osório, F.L., 2018. The Associations Between Oxytocin and Trauma in Humans: A Systematic Review. Front Pharmacol 9, 154.

Glovinsky, D., Kalogeras, K.T., Kirch, D.G., Suddath, R., Wyatt, R.J., 1994. Cerebrospinal fluid oxytocin concentration in schizophrenic patients does not differ from control subjects and is not changed by neuroleptic medication. Schizophr Res $11,273-276$.

Goldman, M., Marlow-O'Connor, M., Torres, I., Carter, C.S., 2008. Diminished plasma oxytocin in schizophrenic patients with neuroendocrine dysfunction and emotional deficits. Schizophr Res 98, 247-255.

Guzel, D., Yazici, A.B., Pek, T.M., Doganay, S., Simsek, A.B.S., Saglam, K., Turan, C., Yazici, E., 2018. Atrial natriuretic peptide and posterior pituitary neurohormone changes in patients with acute schizophrenia. Neuropsychiatr Dis Treat 14, 18551860.

Jobst, A., Dehning, S., Ruf, S., Notz, T., Buchheim, A., Henning-Fast, K., Meißner, D., Meyer, S., Bondy, B., Müller, N., Zill, P., 2014. Oxytocin and vasopressin levels are decreased in the plasma of male schizophrenia patients. Acta Neuropsychiatr $26,347-355$.

Jones, C., Barrera, I., Brothers, S., Ring, R., Wahlestedt, C., 2017. Oxytocin and social functioning. Dialogues Clin Neurosci $19,193-201$.

Kéri, S., Kiss, I., Kelemen, O., 2009. Sharing secrets: oxytocin and trust in schizophrenia. Soc Neurosci 4, 287-293.

Liu, Y., Song, X., Liu, X., Pu, J., Gui, S., Xu, S., Tian, L., Zhong, X., Zhao, L., Wang, H., Liu, L., Xu, G., Xie, P., 2021. Alteration of lipids and amino acids in plasma distinguish schizophrenia patients from controls: a targeted metabolomics study. Psychiatry and clinical neurosciences.

Liu, Y., Tao, H., Yang, X., Huang, K., Zhang, X., Li, C., 2019. Decreased Serum Oxytocin and Increased Homocysteine in FirstEpisode Schizophrenia Patients. Front Psychiatry 10, 217.

Nadeem, Z., Mclntosh, A., Lawrie, S., 2004. Schizophrenia. Evid Based Ment Health 7, 2-3. 
Owen, M.J., Sawa, A., Mortensen, P.B., 2016. Schizophrenia. Lancet 388, 86-97.

Perkovic, M.N., Erjavec, G.N., Strac, D.S., Uzun, S., Kozumplik, O., Pivac, N., 2017. Theranostic Biomarkers for Schizophrenia. Int J Mol Sci 18.

Rubin, L.H., Carter, C.S., Bishop, J.R., Pournajafi-Nazarloo, H., Drogos, L.L., Hill, S.K., Ruocco, A.C., Keedy, S.K., Reilly, J.L., Keshavan, M.S., Pearlson, G.D., Tamminga, C.A., Gershon, E.S., Sweeney, J.A., 2014. Reduced levels of vasopressin and reduced behavioral modulation of oxytocin in psychotic disorders. Schizophr Bull 40, 1374-1384.

Rubin, L.H., Carter, C.S., Bishop, J.R., Pournajafi-Nazarloo, H., Harris, M.S., Hill, S.K., Reilly, J.L., Sweeney, J.A., 2013. Peripheral vasopressin but not oxytocin relates to severity of acute psychosis in women with acutely-ill untreated firstepisode psychosis. Schizophr Res 146, 138-143.

Rubin, L.H., Carter, C.S., Drogos, L., Pournajafi-Nazarloo, H., Sweeney, J.A., Maki, P.M., 2010. Peripheral oxytocin is associated with reduced symptom severity in schizophrenia. Schizophr Res 124, 13-21.

Rubin, L.H., Li, S., Yao, L., Keedy, S.K., Reilly, J.L., Hill, S.K., Bishop, J.R., Sue Carter, C., Pournajafi-Nazarloo, H., Drogos, L.L., Gershon, E., Pearlson, G.D., Tamminga, C.A., Clementz, B.A., Keshavan, M.S., Lui, S., Sweeney, J.A., 2018. Peripheral oxytocin and vasopressin modulates regional brain activity differently in men and women with schizophrenia. Schizophr Res 202, 173-179.

Sasayama, D., Hattori, K., Teraishi, T., Hori, H., Ota, M., Yoshida, S., Arima, K., Higuchi, T., Amano, N., Kunugi, H., 2012. Negative correlation between cerebrospinal fluid oxytocin levels and negative symptoms of male patients with schizophrenia. Schizophr Res 139, 201-206.

Schultz, S.H., North, S.W., Shields, C.G., 2007. Schizophrenia: a review. Am Fam Physician 75, 1821-1829.

Speck, L.G., Schöner, J., Bermpohl, F., Heinz, A., Gallinat, J., Majic, T., Montag, C., 2019. Endogenous oxytocin response to film scenes of attachment and loss is pronounced in schizophrenia. Soc Cogn Affect Neurosci 14, 109-117.

Stilo, S.A., Murray, R.M., 2019. Non-Genetic Factors in Schizophrenia. Curr Psychiatry Rep 21, 100.

Strauss, G.P., Chapman, H.C., Keller, W.R., Koenig, J.I., Gold, J.M., Carpenter, W.T., Buchanan, R.W., 2019. Endogenous oxytocin levels are associated with impaired social cognition and neurocognition in schizophrenia. J Psychiatr Res 112 , 38-43.

Strauss, G.P., Keller, W.R., Koenig, J.I., Gold, J.M., Frost, K.H., Buchanan, R.W., 2015. Plasma oxytocin levels predict social cue recognition in individuals with schizophrenia. Schizophr Res 162, 47-51.

Vargas, G., 2014. Biomarkers in schizophrenia. Biomark Med 8, 1-3.

Wahlberg, K.E., Wynne, L.C., Hakko, H., Läksy, K., Moring, J., Miettunen, J., Tienari, P., 2004. Interaction of genetic risk and adoptive parent communication deviance: Iongitudinal prediction of adoptee psychiatric disorders. Psychol Med 34, 15311541.

Walss-Bass, C., Fernandes, J.M., Roberts, D.L., Service, H., Velligan, D., 2013. Differential correlations between plasma oxytocin and social cognitive capacity and bias in schizophrenia. Schizophr Res 147, 387-392.

Weickert, C.S., Weickert, T.W., Pillai, A., Buckley, P.F., 2013. Biomarkers in schizophrenia: a brief conceptual consideration. Dis Markers 35, 3-9. 


\section{Tables}

ELISA: Enzyme-linked immunosorbent assay. RIA: radioimmunoassay.

Table 2. Summary results of oxytocin levels in individuals with SCZ and healthy controls.

\begin{tabular}{|c|c|c|c|c|c|c|c|c|}
\hline \multirow[t]{3}{*}{ Variables } & \multicolumn{4}{|c|}{ Meta-analysis } & \multicolumn{2}{|c|}{ Heterogeneity } & \multirow{2}{*}{\multicolumn{2}{|c|}{$\frac{\text { Publication bias }}{\text { Egger's test }}$}} \\
\hline & \multirow[t]{2}{*}{ SMD } & \multirow{2}{*}{\multicolumn{2}{|c|}{$95 \% \mathrm{CI}$}} & \multirow[t]{2}{*}{ p-value } & \multirow[t]{2}{*}{$\mathrm{I}^{2}$} & \multirow[t]{2}{*}{$\mathrm{Q}$ test } & & \\
\hline & & & & & & & t-value & p-value \\
\hline \multicolumn{9}{|l|}{ Biomaterial } \\
\hline Plasma & -0.27 & -1.10 & 0.55 & 0.51 & $71 \%$ & 0.00 & 0.37 & 0.72 \\
\hline Serum & -1.74 & -3.22 & -0.26 & 0.02 & $77 \%$ & 0.00 & 7.76 & 0.06 \\
\hline CSF & 0.55 & 0.05 & 1.04 & 0.03 & $50 \%$ & 0.13 & 0.98 & 0.50 \\
\hline \multicolumn{9}{|l|}{ Subgroups } \\
\hline \multicolumn{9}{|l|}{ Plasma } \\
\hline Region/America & -0.17 & -1.35 & 1.01 & 0.77 & $89 \%$ & 0.00 & 0.21 & 0.86 \\
\hline Region/Europe & -0.37 & -1.75 & 1.00 & 0.59 & $85 \%$ & 0.00 & 0.60 & 0.65 \\
\hline Ethnicity/Caucasian & -0.70 & -1.79 & 0.38 & 0.20 & $89 \%$ & 0.00 & 0.03 & 0.97 \\
\hline Method/RIA & -0.18 & -0.94 & 0.58 & 0.63 & $84 \%$ & 0.00 & 0.17 & 0.87 \\
\hline \multicolumn{9}{|l|}{ Serum } \\
\hline Region/America & -0.14 & -0.38 & 0.09 & 0.22 & $10 \%$ & 0.96 & 0.06 & 0.96 \\
\hline Method/ELISA & -2.18 & -4.22 & -0.14 & 0.03 & $78 \%$ & 0.00 & 9.43 & 0.06 \\
\hline Gender/Male & -0.85 & -1.83 & 0.12 & 0.08 & $80 \%$ & 0.00 & 7.01 & 0.06 \\
\hline Gender/Female & -0.01 & -0.37 & 0.34 & 0.93 & $10 \%$ & 0.85 & 1.16 & 0.45 \\
\hline
\end{tabular}

The significance is shown in bold.

\section{Figures}


Table 1. Characteristics of the studies included in the meta-analysis.

\begin{tabular}{|c|c|c|c|c|c|c|c|c|c|c|c|c|c|c|}
\hline \multirow[t]{3}{*}{ Author } & \multirow[t]{3}{*}{ Year } & \multirow[t]{3}{*}{ Country } & \multirow{3}{*}{$\begin{array}{l}\text { Assay } \\
\text { method }\end{array}$} & \multirow[t]{3}{*}{ Time sampling } & \multicolumn{5}{|c|}{ Cases } & \multicolumn{5}{|c|}{ Controls } \\
\hline & & & & & \multirow[t]{2}{*}{$\mathbf{N}$} & \multirow[t]{2}{*}{$\begin{array}{l}\text { Age } \\
\text { mean }\end{array}$} & \multirow[t]{2}{*}{ Males } & \multicolumn{2}{|c|}{$\begin{array}{l}\text { Oxytocin } \\
(\mathrm{pg} / \mathrm{ml})\end{array}$} & \multirow[t]{2}{*}{$\mathbf{N}$} & \multirow[t]{2}{*}{$\begin{array}{l}\text { Age } \\
\text { mean }\end{array}$} & \multirow[t]{2}{*}{ Males } & \multicolumn{2}{|c|}{$\begin{array}{l}\text { Oxytocin } \\
(\mathrm{pg} / \mathrm{ml})\end{array}$} \\
\hline & & & & & & & & Mean & SD & & & & Mean & $\mathrm{SD}$ \\
\hline \multicolumn{15}{|l|}{ Plasma } \\
\hline Goldman, & 2008 & USA & RIA & Evening & 15 & 40.8 & 9 & 222.33 & 227.33 & 7 & 34.7 & 4 & 240 & 224 \\
\hline \multicolumn{15}{|l|}{ M. (Goldman } \\
\hline \multicolumn{15}{|l|}{ et al., 2008) } \\
\hline Walss-Bass, & 2013 & Portugal & ELISA & - & 60 & 42.1 & 45 & 308.04 & 136.99 & 20 & 39.6 & 14 & 199.33 & 119.42 \\
\hline \multicolumn{15}{|l|}{ C. (Walss- } \\
\hline \multicolumn{15}{|l|}{ Bass et al., } \\
\hline \multicolumn{15}{|l|}{ 2013) } \\
\hline Strauss, G. & 2015 & USA & RIA & - & 40 & 43.7 & 28 & 24.46 & 7.54 & 22 & 43.1 & 14 & 19.66 & 5.86 \\
\hline \multicolumn{15}{|l|}{ P. (Strauss et } \\
\hline \multicolumn{15}{|l|}{ al., 2015) } \\
\hline Aydin, & 2019 & Turkey & ELISA & Morning & 34 & 30 & 22 & 300.46 & 130.21 & 31 & 29.6 & 13 & 609.89 & 217.72 \\
\hline \multicolumn{15}{|l|}{ O. (Aydın et } \\
\hline al., 2019) & & & & & & & & & & & & & & \\
\hline Strauss, G. P. & 2019 & USA & RIA & - & 30 & 46.6 & 22 & 9.93 & 5.06 & 21 & 42.5 & 8 & 16.64 & 7.08 \\
\hline (Strauss et & & & & & & & & & & & & & & \\
\hline al., 2019) & & & & & & & & & & & & & & \\
\hline Speck, L. & 2019 & Germany & RIA & - & 35 & 40.4 & 23 & 4.59 & 3.35 & 35 & 36 & 23 & 5.48 & 4.5 \\
\hline G. (Speck et & & & & & & & & & & & & & & \\
\hline al., 2019) & & & & & & & & & & & & & & \\
\hline Serum & & & & & & & & & & & & & & \\
\hline Rubin, L. & 2010 & USA & RIA & - & 50 & 30.92 & 27 & 286.48 & 210.44 & 58 & 27.74 & 27 & 312.48 & 203.07 \\
\hline H. (Rubin et & & & & & & & & & & & & & & \\
\hline al., 2010) & & & & & & & & & & & & & & \\
\hline Rubin, L. & 2013 & USA & ELISA & - & 38 & 24.3 & 24 & 356.8 & 242.22 & 38 & 28 & 24 & 385.13 & 238.15 \\
\hline H. (Rubin et & & & & & & & & & & & & & & \\
\hline al., 2013) & & & & & & & & & & & & & & \\
\hline Guzel, D. & 2018 & Turkey & ELISA & - & 34 & 38.9 & 34 & 12.95 & 4.84 & 24 & 40.7 & 24 & 35.41 & 12.75 \\
\hline (Guzel et al., & & & & & & & & & & & & & & \\
\hline 2018) & & & & & & & & & & & & & & \\
\hline Rubin, L. & 2018 & USA & ELISA & Morning & 35 & 39 & 23 & 5.95 & 0.7 & 60 & 32.6 & 24 & 6.1 & 0.8 \\
\hline H. (Rubin et & & & & & & & & & & & & & & \\
\hline
\end{tabular}


al., 2018)

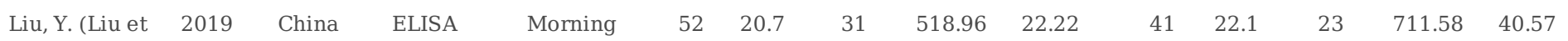
al., 2019)

Cerebro-spinal fluid

$\begin{array}{lllllllllllllll}\text { Beckmann, } & 1985 & \text { Germany } & \text { RIA } & \text { Morning } & 28 & 30.6 & 28 & 11.74 & 4.99 & 16 & 35 & 13 & 7.11 & 4.03\end{array}$

H. (Beckmann

et al., 1985)

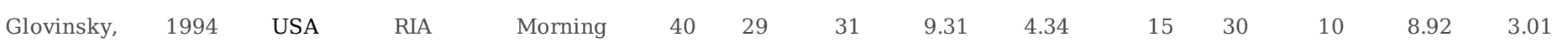

D. (Glovinsky

et al., 1994)

$\begin{array}{lllllllllllllllll}\text { Sasayama, } & 2012 & \text { Japan } & \text { ELISA } & - & 27 & 42.6 & - & 10.52 & 4.66 & 21 & 38.3 & - & 8.01 & 3.52\end{array}$

D. (Sasayama

et al., 2012)

Systematic review

\begin{tabular}{|c|c|c|c|c|c|c|c|c|c|c|c|c|c|c|}
\hline $\begin{array}{l}\text { Keri, S. (Kéri } \\
\text { et al., 2009) }\end{array}$ & 2009 & Hungary & ELISA & Morning & 50 & 47.9 & 16 & - & - & 50 & 47.8 & 16 & - & - \\
\hline Jobst, & 2014 & Germany & ELISA & Morning & 41 & 24.9 & 41 & - & - & 45 & 24.6 & 45 & - & - \\
\hline \multicolumn{15}{|l|}{ A. (Jobst et } \\
\hline \multicolumn{15}{|l|}{ al., 2014) } \\
\hline Rubin, L. & 2014 & USA & ELISA & Morning & 57 & 35.3 & 35 & - & - & 66 & 37.1 & 28 & - & - \\
\hline \multicolumn{15}{|l|}{ H. (Rubin et } \\
\hline al., 2014) & & & & & & & & & & & & & & \\
\hline
\end{tabular}


Records identified through databases searching ( $n=302)$
Additional records identified through other sources ( $n=7$ )

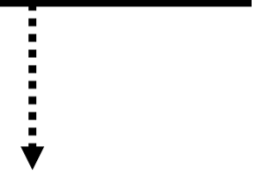

Records after duplicates removed

( $n=164)$
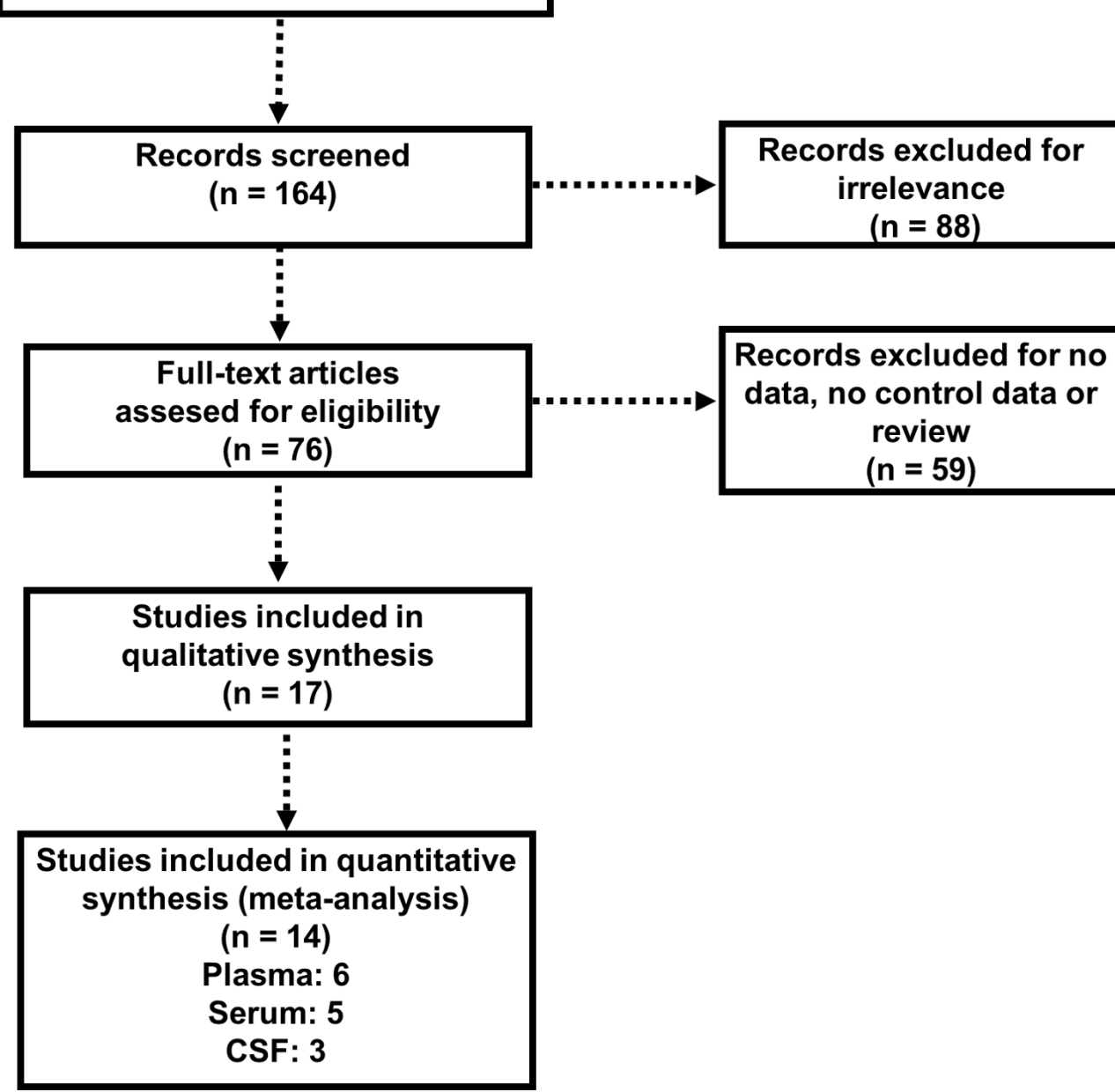

Figure 1

Flow diagram of the study selection process. 


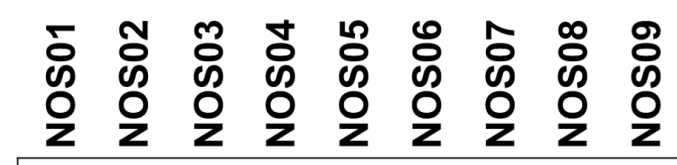

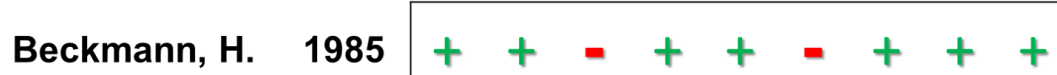

Glovinsky, D. $1994++=++=+++$

Goldman, M. $2008++=++++++$

Keri, S. $2009++=++=+++$

Rubin, L. H. $2010+++++-+++$

Sasayama, D. $2012++-++-+++$

Walss-Bass, C. $2013++=++++++$

Rubin, L. H. $2013++=++++++$

Jobst, A. $2014++=++++++$

Rubin, L. H. $2014++-++++++$

Strauss, G. P. $2015+++++++++$

Guzel, D. $2018++-++-+++$

Rubin, L. H. $2018+++++++++$

Aydin, 0. $2019+++++++++$

Strauss, G. P. $2019++-++-+++$

Liu, Y. $2019+++++++++$

Speck, L. G. $2019+++++++++$

Figure 2

Quality ratings for the studies included according to the Newcastle-Ottawa quality assessment scale. "+" denotes one point and "-" indicates no information. 
Study

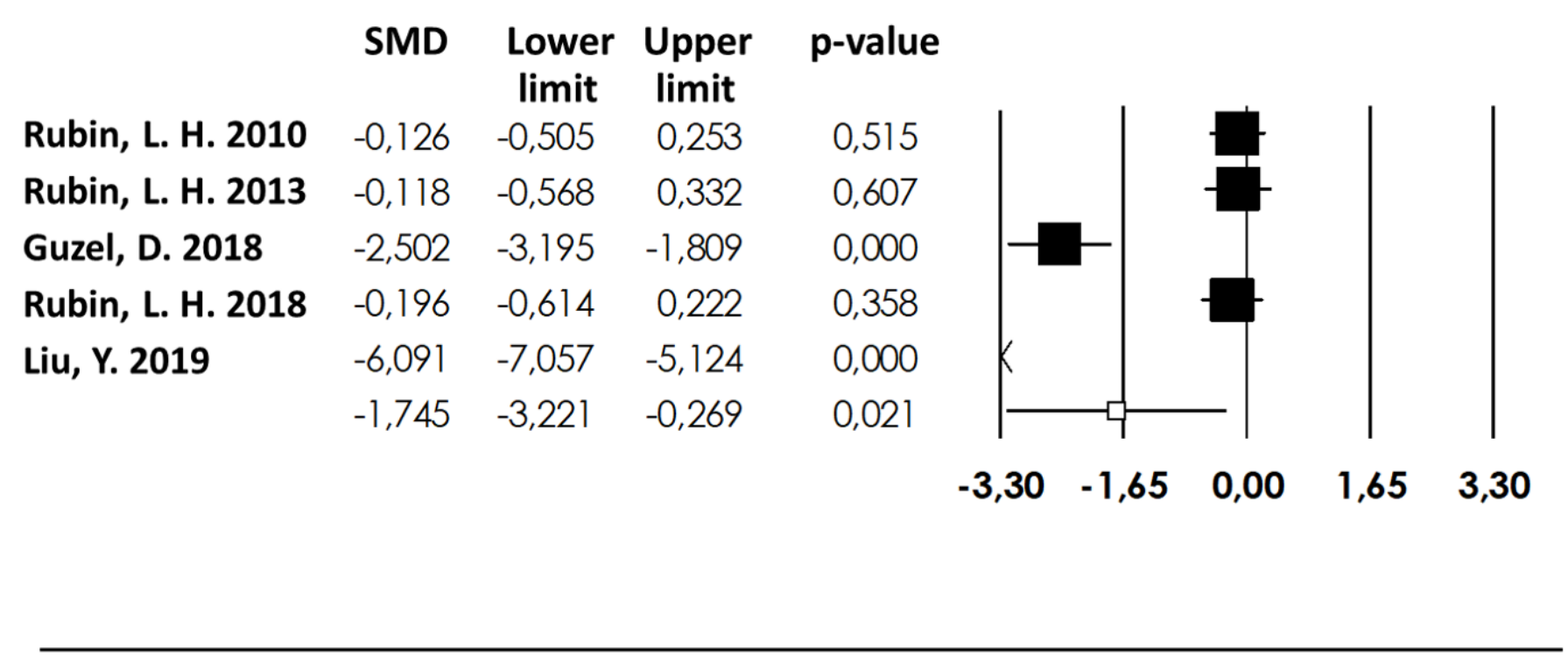

Figure 3

Forest plot for the meta-analysis of serum oxytocin levels in individuals with schizophrenia compared to healthy controls.

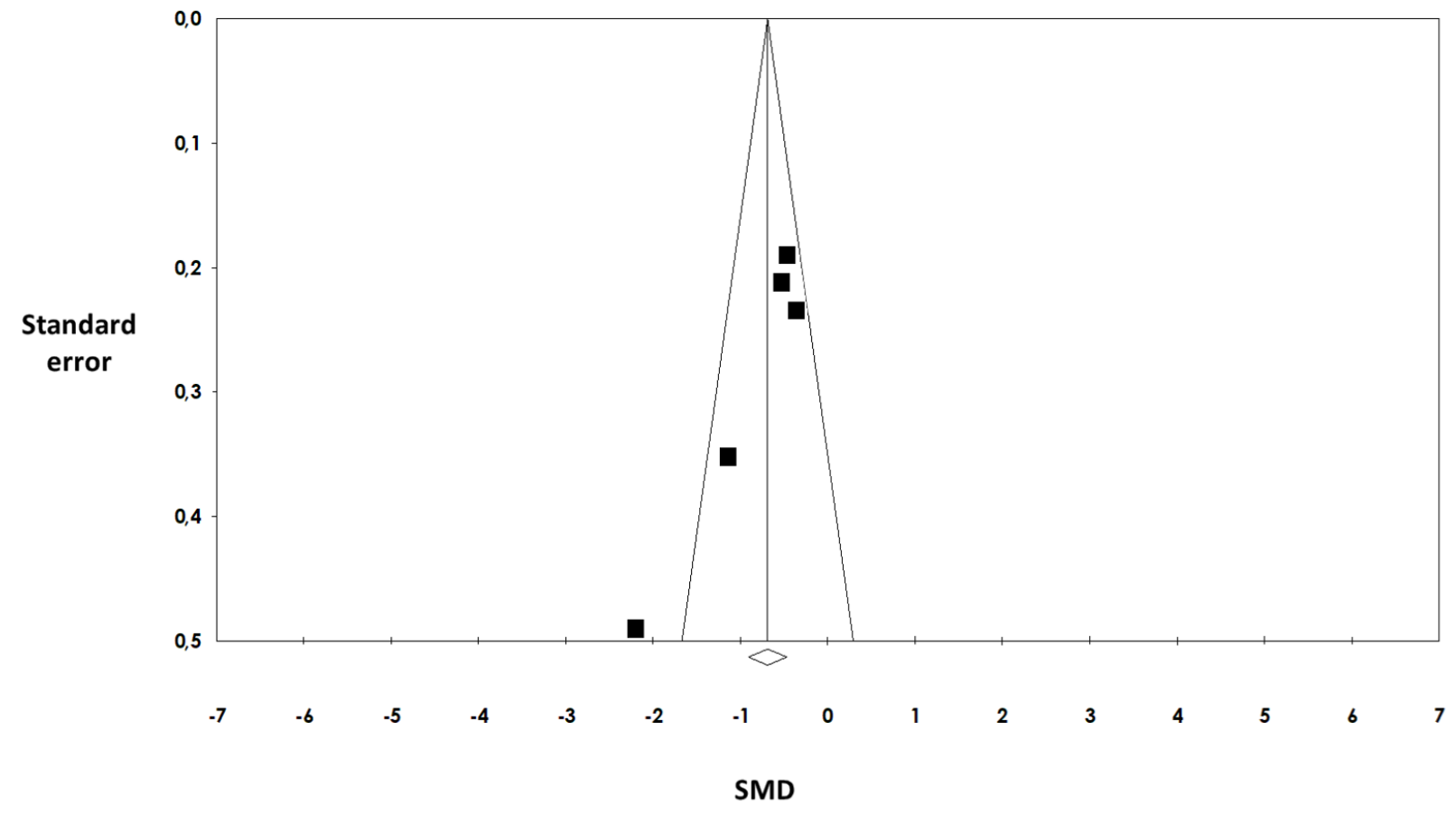

Figure 4

Funnel plot for the meta-analysis of serum oxytocin levels in individuals with schizophrenia compared to healthy controls. 